\title{
MORTE E FILOSOFIA - SOBRE O DESEJO DE IMORTALIDADE ENTRE OS GREGOS
}

\author{
Maria Carolina Alves dos SANTOS ${ }^{1}$
}

- RESUMO: Enfoca-se aqui a vinculação íntima entre a exaustiva busca empreendida pelo espírito grego para edificar em terreno sólido as colossais fundações de uma ciência dos primeiros princípios, e o que supõe-se ser sua motivação secreta e última, a aspiração pela eternidade, o mais universal e genuíno desejo presente em todo ser humano, não ser obliterado pelo tempo.

- PALAVRAS-CHAVE: Morte; filosofia; imortalidade; desejo; alma; vida; natureza.

Não compreendemos muito bem como os Antigos sentiam as coisas as mais banais, as mais correntes, por exemplo, o dia e o despertar: como eles acreditavam no sonho, a vigília tinha para eles uma outra luz. Ela era mesmo o essencial da vida, esclarecida por esse crepúsculo da morte e de sua significação: nossa morte é para nós, sem dúvida, uma outra morte.

(Nietzsche, Le gai savoir)

Sopra ali a brisa do oceano

E chamejam flores de ouro

Umas em árvores que cintilam na terra

Outras nutridas pela água

E os bem-aventurados as tecem para coroar-se com elas..

(Píndaro, fr.129-30)

\section{I}

O que teria impelido o espírito grego na busca de uma visão do mundo circundante sob novas luzes? A súbita apreensão do incessante e brutal escoamento da vida? A consciência do modo fugaz, inconsistente e finito de seu existir? A constatação trágica do jogo absurdo em que o viver consiste - espetáculo atordoante da morte de uma significação fundamental - não é geradora do formidável pathós que inspirou um novo discurso, mais racional e ordenado, sobre os fundamentos da aparentemente caprichosa dimensão do devir? Afirma Rodhe:

\footnotetext{
1 Departamento de Filosofia - Faculdade de Filosofia e Ciências - UNESP - 17525-900 - Marilia - SP.
} 
Não há nada, na imediata experiência do homem, que exija menos ser demonstrado ou explicado, nada mais evidente por si mesmo que o fenômeno da vida, o fato da nossa própria vida. A cessação de uma coisa tão evidente como a existência, suscita em troca, o estupor dos homens, sempre e aonde quer que se apresente. (1973, p.19)

Dominado por forte carência da presença de algo permanente, seguindo o mais genuíno impulso da alma grega, o filósofo converge seu olhar clarividente para as ainda misteriosas instâncias situadas nos confins do universo e cria a metafísica. Essa síntese inteligente, espiritual, intuitiva, resulta de uma soberana força motriz da natureza humana, que pode ser nomeada desejo de imortalidade.

Desejo significa, para o grego, ardoroso impulso (hormé, oréxis), o élan que o faz tender com impaciência a um fim, à satisfação disso que lhe falta. Essa carência exemplar, a aspiração pela eternidade, desencadeada pela implacável fugacidade da vida humana, é a causa secreta que nos primórdios da civilização ocidental alimentou a marcha do filosofar: como discurso originário da indigência, a filosofia buscou, com paixão, recurso num saber mais sólido, fundado em princípios intemporais e imutáveis, que pudesse emprestar um sentido mais pleno e eternitário à história do homem.

Nas extraordinárias aventuras que o espírito grego empreende então, valendo-se da elevada capacidade de abstração que o caracteriza, procura explorar o real na totalidade de seus aspectos. E foi capaz de conceber, no curso de um breve tempo da história do Ocidente, a ciência, a arte, a filosofia. Entre Homero e Aristóteles - período em que eclodem as idéias dominantes instituidoras dos gêneros poéticos, das artes plásticas, da arte dramática, das matemáticas, da astronomia, da história, da política, da teoria do conhecimento, da ética, da filosofia política, da lógica, da filosofia da linguagem, da estética - decorreram apenas 400 anos.

A pura essência desta vasta herança, cujo valor incalculável não cessa de evidenciar-se para nós, seus beneficiários, está magistralmente expressa em prolíferos discursos acerca da substância primordial e única, estofo originário de tudo, os logoi peri physeos. Instauram as grandiosas fundações de uma ciência dos primeiros princípios. Na tentativa de converter toda diversidade numa unidade absoluta, denominador comum de toda pluralidade fenomênica, os primeiros filósofos lançam as bases de um modo universal de compreender o mundo. "Tales viu a unidade do ser e quando quis exprimi-la falou da água", afirma Nietzsche (1969, p.164).

A motivação última de todo esse esforço de legitimação do saber num plano transcendente ao que se processa o ciclo da geração, corrupção e morte, não é outra senão a de ultrapassar a incompletude inerente à condição humana, marcada pelo eterno fluxo do que é mortal. O desejo de perpetuar-se constitui a fonte da aspiração pela sabedoria, porque por meio dela triunfa-se sobre os aspectos vãos e transitórios do mundo das aparências, perpetuando a vida para além da morte. O homem é um animal metafísico porque é um animal mortal, que tem sede de perenidade e fome do absoluto. Observa Godel (1940, p.36) que, em todos os espíritos contemplativos do século VI, revela-se um mesmo desejo transcendente de elevar-se acima do plano da instabilidade, do movimento, da multiplicidade das formas sensíveis, afim de atingir o repouso no reino da imutável realidade. 
Ante a perspectiva melancólica da degradação inexorável de tudo que é gerado, buscando conferir à própria existência um valor mais alto, o filósofo assemelha-se aos heróis lendários, em sua aspiração pelos desígnios que advém dos grandes feitos. O que define um herói são os atos que ele ousa realizar e executa com sucesso, condensando todas as virtudes e perigos da ação humana. Diz Vernant:

Ele figura, de certo modo, o ato em estado exemplar, o ato que cria, que inaugura, que inicia (herói civilizador, inventor, fundador de cidades ou linhagens, iniciador); ato enfim que transcende a condição humana e, como um rio que sobe até a sua fonte, vem juntar-se à força e vence a morte. (1973a, p 287)

Os primeiros pensadores empreendem a conquista dos intrincados domínios do supra-sensível, e dada a enorme importância que atribuem ao Lógos, fazem-no depositário das vitórias de sua inteligência sobre a Fatalidade, a Necessidade, o Destino e a Morte. Formulados com epítetos que se tornaram paradigmáticos - Indestrutível, Imperecedouro, Imortal, Eterno - seus lógoi são instauradores da Ordem, da Harmonia, da Justiça, do Bem: adquirem, por isso, um poder de clarificação que lhes confere, no quadro conceitual então nascente, o estatuto de verdades essenciais. Porém, movimentam-se ainda, no âmbito das grandes oposições estabelecidas pelo pensamento religioso entre uma série de termos antinômicos: os deuses - os homens; o invisível - o visível; os eternos - os mortais; o permanente - o mutante; o puro - o impuro (Vernant, 1964, p.323). Eles se apresentam, eles mesmos, como sucessores dos profetas, adivinhos e poetas, como detentores de segredos mágicos, de faculdades extraordinárias, que lhes propicia um saber privilegiado, e a permanente convivência com o divino. Consideram-se mestres da Verdade (Detiènne, 1988, p.73). ${ }^{2}$

\section{II}

Do cerne da prodigiosa indagação sobre a physis empreendida nesses primórdios da civilização ocidental, emerge a não menos fecunda investigação sobre a natureza do homem, tema tão inquietante quanto aquele, cuja essência é também vedada ao nosso conhecimento sensível. É então que se descobre uma dimensão no seu interior, inteiramente nova, identificada a uma força misteriosa, sobrenatural, impalpável, aparentada a estranha força vital que anima e move a totalidade cósmica. Sobre isso, afirma Anaxímenes: "Como nossa alma, que é o ar, soberanamente nos mantém unidos, assim também todo o cosmo sopro e ar o mantém" (Aécio, I, 3, 4, in Os filósofos pré-socráticos, 1972).

As enigmáticas sentenças de Heráclito, proferidas com fervor profético de quem quer expressar verdades eternas, são destinadas a despertar os homens de seu torpor e renovar-lhes a vida. Pois, entre eles, "apenas alguns têm como aspiração primeira

2 "O problema do divino ocupa, nas especulações dos primeiros filósofos um lugar muito mais amplo do que com freqüência estamos dispostos a reconhecer", afirma Jaeger (1978, p.12). 
alcançar a fama imortal e tudo fazem para obtê-la, os 'aristoi'. Os 'polloi' (os numerosos) interessam-se somente pelo sustento cotidiano, deixam-se absorver pelo presente, e tal como os animais não pensam na morte": "uma só coisa escolhem os melhores contra todas as outras, um rumor de glória eterna contra as (coisas) mortais; mas a maioria está empanturrada como animais" (fr.29).

Estando entre os anistós, Heráclito traça solitariamente seu caminho em busca da imortalidade; "Procurei a mim mesmo" (fr.101). Intuitivamente, aprende tudo de si mesmo, inclusive as insondáveis dimensões do ilimitado Krátos que o habita e lhe infunde vida: "Limites de alma não os encontrarias, todo caminho percorrendo; tão profundo logos ela tem" (fr.45).

E, se sua sabedoria veio pelo estudo de si mesmo, ela não consiste em suas opiniões particulares apenas, mas no que é comum a todos, o lógos, que orienta a totalidade do real. Ele está entre os poucos que têm acesso ao mundo intemporal e invisivel dos deuses que "possuem o conhecimento que tudo dirige através de tudo" (fr.41, p.89), por isso pode assegurar que a inteligência humana é uma parcela da inteligência divina: "comum é a todos o pensar" (fr.113).

A aspiração dos filósofos precursores por conquistar pelo pensamento e pela investigação novas significações sobre o real encontra forte estímulo nas concepções de mundo preexistentes, recobertas que estão com o véu das representações míticas. Sobretudo quanto à problemática inerente ao vasto material oriundo do passado arcaico, relativo à origem e destino da psyché, ser espiritual e imortal, ordenador da esfera interior do homem, a semelhança do ser divino que domina dinamicamente 0 cosmo. ${ }^{3}$ Da imortalidade grandiosa da palavra original sobre essas representações, a nova criação retira seu alento vital para uma compreensão mais profunda do significado da vida humana. A partir delas, desenvolve-se uma doutrina segundo a qual a alma, sendo imortal, renasce sem cessar transmigrando de um corpo a outro; e a morte, longe de ser o fim de um processo irreversível, é uma nova etapa em um ciclo que se repete: a vida sucede à morte, assim como o sono à vigília. O que pode libertar a alma dos ciclos consecutivos é a vida virtuosa. A virtude é o agente eficaz, colaborador para um destino superior aos dos animais, análogo ao dos seres divinos, a imutável e permanente existência num ciclo acabado, único e eterno. ${ }^{4}$

Pitágoras, tido como uma divindade encarnada por sua excepcional sabedoria e memória, é capaz de recordar-se de vinte vidas anteriormente vividas. A persistên-

3 Alguns poemas de Homero exprimem a idéia do caráter transitório da vida humana e do inevitável avanço do tempo. Há a célebre metáfora sobre a geração dos homens e sua semelhança com o crescimento e a queda das folhas na Iliada (1952, VI, 146). Outros exprimem, entretanto, a crença segundo a qual o homem gozaria de uma certa forma de existência após a morte: afirma na Odisséia que a alma desce para o Hades ainda que para gozar de uma vida de ordem inferior (1947, XI, 488). Os poetas líricos veiculam uma concepção mais definida sobre a imortalidade vínculada à crença na transmigração das almas. Segundo Píndaro, a função poética exige a presença da força sobrenatural de Mnemosyne: o poeta adquire então um saber de caráter divinatório, verá o invisivel (Vernant, 1973b, p.73).

4 O "sempre" que caracteriza a vida dos deuses significa a cessação do perpétuo recomeçar, a preservação da destruıção, a permanência em uma identidade eternamente imóvel (Vernant, 1973b, p.90-1). 
cia de reminiscências inalteradas de uma incarnação para outra ele obtinha pela prática intensiva de exercícios de memória que lhe permitiam rememorar erros antigos, e assim expiá-los. Esse esforço de recuperação retrospectiva da trama de existência passadas adquire uma função purificatória e tem um alcance escatológico. Uma vez recobrada a pureza originária, a alma evade-se, enfim, da sucessão dos ciclos de nascimento, elevando-se a uma forma de existência intemporal e divina: "os homens morrem porque não são capazes de juntar o começo ao fim", dizia Alcmeão de Cróton (fr.2). Reunindo-os pela reminiscência, reconquista-se, segundo essa fórmula enigmática, o tempo em sua totalidade e a libertação da morte.

Empédocles também é um theios anér venerado, considerado por todos um deus entre os mortais, já liberto da condição humana e de suas inquietudes. Segundo diz, os homens comuns têm um rápido destino porque, para ele, a vida está limitada entre o nascimento e a morte; somente para o que possui inteligência do todo, o sábio, não há começo nem fim, mas o ciclo das metamorfoses (Sobre a Natureza, fr.2, 8, 15, 17). E se os homens comuns esquecem seu passado a cada renascimento, aquele que guarda a lembrança de tudo, das múltiplas reencarnações nos quatro elementos, pelo seu saber é o condutor deles. "Já com efeito eu outrora fui menino, menina, arbusto, passarinho e, do mar saltando, mudo peixe" (Purificações, fr.117).

A alma, essa força misteriosa que está presente na natureza toda, nos animais, nas plantas, no homem, progride ou regride nos ciclos reencarnatórios, nas diferentes espécies de seres, conforme a maneira como viveu. Alguém que em suas experiências temporais anteriores conseguir transcender a perspectiva das múltiplas experiências fragmentárias e efêmeras, pela prática de exercícios de reminiscência e adequação às regras de vida ascética, apreenderá a unidade da própria história pela recordação de sua verdadeira identidade.

O esquecimento está vinculado ao devir humano, que é o tempo próprio da morte; e a memória, pela ligação que estabelece entre o passado e o presente, patrocina a imortalidade. Mnemosyne é uma força sobrenatural que ultrapassa o homem, à qual se atribui um estatuto divino. Cultuá-la supõe esforço, exercício incessante, que the franqueie a participação no poder de rememoração. O indivíduo que empreende essa conquista conhecerá não somente seu passado particular, mas a ordem geral e cósmica, que é impessoal. Restabelecerá, assim, sistematicamente, a ligação com a natureza toda, com o conjunto dos tempos, com a totalidade do ser: torna-se então onisciente, une-se com o divino, diviniza-se a si próprio (Vernant, 1973b, p.71).

\section{III}

A filosofia de Platão amalgama crenças, doutrinas e vocabulários, pertinentes ao tema do desejo de imortalidade, subjacentes à venerável tradição (o palaiós lógos) e ao pensar originário dos que o precederam, transpondo-os aos termos singulares de sua reflexão para perpetuá-los sob uma nova óptica. No Ménon, funde a doutrina 
da alma imortal com a teoria epistemológica da reminiscência: a teoria do conhecimento vincula-se intimamente à escatologia pela noção da anámnesis. Fundamentando-se na célebre doutrina, ouvida de "homens e mulheres versados em coisas divinas" - de que toda aprendizagem genuína é reminiscência porque a alma nasceu muitas vezes e nada há que não tenha aprendido antes - deduz sua imortalidade (85b). Na theoria platônica, a Anámnesis não mais concerne à recuperação do conhecimento do passado primordial ou das vidas pregressas, mas das Idéias, que são as verdades constitutivas do real. Recordar significa obter sabedoria pela transcendência do sensível, pelo contato com o mundo das idéias eternas, pela contemplação desses seres imutáveis e divinos.

No Fédon, Platão defende a tese de uma imortalidade pessoal e contemplativa. A alma de Sócrates não é definida como um ser espiritual estranho que atua através dele; identifica-se ao indivíduo singular que é ele próprio, responsável pelo rumos de seu destino após a morte. Ele exorta, longamente, cada um a ocupar-se com afinco da atividade libertadora das vicissitudes da vida terrestre, para garantir a eterna beatitude. Situado na confluência das diversas correntes anteriores, ante a concepção da alma em exílio na esfera corpórea até a total expiação das faltas cometidas em outras existências, elege a filosofia como veículo excelente de reminiscência, purificação e de salvação: a roda das reencarnações será definitivamente interrompida por quantos souberem filosofar no sentido correto do termo, segundo a pureza e a justiça. Bem por isso, Sócrates está alegre e confiante diante da morte; enquanto viveu, não cessou de preparar-se para ela, intensamente impelido pelo desejo, o mais genuíno em todo ser humano, de perdurar na eternidade. Sua grande esperança (elpís megále) é estar, em breve, junto aos seres bem-aventurados, amos em tudo excelentes, os deuses que habitam a superfície da verdadeira terra (63c-65c, 114c).

A metafísica arquitetada por Platão, nesse diálogo, está solidamente edificada sobre vigorosos alicerces - a constituição natural da alma, por essência oposta à idéia da morte - que sustentam a plena certeza da imortalidade da alma. ${ }^{5}$ De acordo com a bela fórmula conclusiva da complexa discussão, a natureza da alma tem por atributo essencial a Vida (Fédon, 105d), e porque sua natureza é tal, jamais transmuta-se em seu contrário: ainda que este se aproxime, ela permanece inalteradamente a mesma sempre (102d-103b). A morte significa a total separação da alma das coisas corpóreas e sensiveis, a cujo processo o ato de filosofar identifica-se, reduzindo-se a uma melete thanatou, um aprendizado do morrer. Chegado o momento, alça seu vôo imperturbável em direção à vida eterna entre as realidades divinas, com as quais possui afinidade (syngenés) natural (80a). ${ }^{6}$

5 A imortalidade da alma, afirma Robledo (1986, p.329), é algo que reclama imperiosamente, como sua mais própria razão suficiente, toda a filosofia platônica sob qualquer de seus aspectos.

6 Também para Aristóteles, o intelecto é o que há em nós de divino. Sendo divino, a vida conforme ele será divina. Sua atividade, a contemplação é perfeita, propicia o exercício das potencialidades humanas atualizando o que há de mais elevado nelas: a vida contemplativa realiza a tangência com a divindade, cuja vida só pode ser contemplativa. Os homens, sendo mortais, não devem ater-se às coisas mortais, mas fazer-se imortal, vivendo segundo a parte superior que existe nele (Et. Nic. $\mathrm{K}_{7}, 1177 \mathrm{~b}_{19}-1178 \mathrm{a}_{2}$, in Aristóteles, 1973, p.429). 
O coroamento de todo esforço exaustivo, para ascender no rude caminho vertical que conduz gradualmente à imortalidade, é a assimilação a Deus (ómoiosis théos). No Timeu, Platão afirma:

Aquele que aplicou-se no amor pelo saber e em pensamentos verdadeiros, e que exerceu, antes de tudo, esta parte de si mesmo, obterá, imagino, com toda necessidade, pensamento imortais e divinos. Ao conseguir entrar em contato com a verdade e, na medida em que a natureza humana pode participar da imortalidade, será cumulado dela, porque rende culto, sem cessar, à divindade.?

Contrariamente ao oráculo de Delfos - que proclama a necessidade do autoconhecimento para o homem poder compreender que não é um deus, e nem pode pretender tornar-se um -, o pensamento platônico põe como a mais alta aspiração humana o profundo conhecimento desse ser divino que em cada um é ele mesmo, apenas saciável pelo ardoroso empenho em tornar-se, tanto quanto possível, semelhante a ele. A freqüentação especulativa do que é naturalmente ordenado e divino estimula a dynamis interna do homem a imitá-lo, comportando-se também de modo ordenado e divino.

Movido pelo infatigável desejo de perpetuar-se, que constitui a própria substância do gênero humano, Platão concebeu uma obra magnífica e fecundante. Buscando imortalizar-se pela similitude com o pensamento dos deuses, articula dialeticamente representações imaginárias a conceituações racionais sobre o Ser, os diálogos que se legitimam, ao mesmo tempo, na dimensão da História, como manifestações do "desejo de sabedoria": cria, assim, para si mesmo, também uma memória entre os homens, para que o tempo não o oblitere. Assim, os discursos platônicos são relatos vivos das palpitantes aventuras em que consiste a vita contemplativa, verdadeiros dramas escritos em prosa, sobre as perplexidades e antinomias da psyché percorrendo domínios intrincados do Inteligível, em busca de Definições, Imagens, Ciência e Essência do que é o Real, cujo estatuto é permanente e divino, para assimilar-se a ele. ${ }^{8}$

Ao homem é dado, diz Platão no Banquete, duas maneiras de imortalizar-se; uma inferior, comum com os animais, a geração humana; outra superior, que é propriamente humana, "segundo a alma" (Katá tén psychén) da qual resultam os mais belos filhos espirituais (206c-209b). Quando está, pois, fecundada e encontra um belo corpo e uma bela alma, gera filhos mais imortais que os dos homens, os discursos sobre a Virtude (Ibidem). Nos vigorosos traços da imortal linhagem de Platão está presente a intensa luminosidade das Idéias que fermentam em seu espírito, e que forneceram a centelha a partir da qual toda a filosofia do ocidente incandesceu.

Sua concepção escatológica da morte, posta em contínua interação com a Vida - uma vida desembaraçada de seus entraves mortíferos para a alma - cai sobre nossa civilização (que não é ainda "a" civilização) como uma faísca esclarecedora, confe-

7 Cf. 90, b-c, Leis IV, 716 c-d, Teeteto 176b, República IV, 500c-d, in Platão, 1950.

8 Cf. Carta VII, 342a-e, in Platão, 1950. 
rindo dignidade ontológica a um fenômeno que, para muitos, reduz-se a mera dissolução biológica, ou é entendido como o contrário conflitante da vida. Situado estrategicamente na confluência das diversas concepções dos predecessores, a de Platão oferece um quadro sinóptico dessa questão essencial para os gregos, pelo elevado sentimento que têm da dignidade humana e do sentido nobre da vida, ainda não explorada o suficiente por nós na atualidade. Em nossa cultura crepuscular, na qual quase não nos ocupamos mais em "aprender a morrer", submetendo permanentemente os nossos valores a desafiadoras indagações e reformulações, a morte permanece algo enigmático ou arbitrário, ou como diz Nietzsche, "uma outra morte, sem dúvida" (1950, p.47).

SANTOS, M. C. A. dos. Death and philosophy - the desire for immortality among the Greeks. Trans/Form/Ação (São Paulo), v.19. p.185-193, 1996.

- ABSTRACT: This paper focuses on the intimate associations between the exhaustive attempt, undertaken by the Greek spint, to build on solid ground their colossal foundations of a science of first principles, and that which one may suppose to be its a secret and ultimate motivation, namely, the aspiration after eternity, the most universal and genuine desire present in every human being, not to be obliterated by time.

- KEYWORDS: Death; philosophy; immortality; desire; soul; life; nature.

\section{Referências bibliográficas}

ARISTÓTELES. Ética a Nicômaco. Trad. L. Vallandro e G. Bornheim. São Paulo: Abril Cultural, 1973.

OS FILÓSOFOS Pré-Socráticos. Introdução, tradução e notas de G. A. Bornheim. São Paulo: Cultrix, 1972.

DETIENNE, M. Os mestres de verdade. Rio de Janeiro: Zahar, 1988.

GODEL, R. Recherche d'une foi. Paris: Belles Lettres, 1940.

HOMĖRE. L'Iliade. Trad. E. Lassere. Paris: Garnier, 1952.

L'Odyssée. Trad. M. Dufour et J. Raison. Paris: Garnier, 1947.

JAEGER, W. La teologia de los primeiros filosofos griegos. México: Fondo de Cultura Economica, 1978.

NIETZSCHE, F. La naissance de la philosophie à l'époque de la tragédie grecque. Trad. G. Bianquis. Paris: Gallimard, 1969.

Le gai savoir. Paris: Gallimard, 1950.

PLATON. Oeuvres Complètes. Trad. L. Robin. Paris: Gallimard, 1950.

OS PRÉ-SOCRÁTICOS: fragmentos, doxografia e comentários. Seleção de textos e supervisão de J. C. de Souza. Trad. J. C. de Souza et al. São Paulo: Abril Cultural, 1973. 
ROBLEDO, A. G. Platón. México: Fondo de Cultura Economica, 1986.

RODHE, E. Psiquê. Barcelona: Editorial Labor, 1973.

VERNANT, J. P. A pessoa na religião. In:

Mito e pensamento entre os gregos. São Paulo: Difel, 1973a.

Aspectos míticos da memória e do tempo. In:

Mito e pensamento entre os gregos. São Paulo: Difel, 1973b.

L'évolution des idées en Chine et en Grèce du VIe au II siècle avant notre ère. Bulletin Annuel G. Budé, n.3, 1964. 